\title{
El reto sindical de la reestructuración universitaria
}

\author{
Han pasado ya cuarenta años desde aquel 30 de abril de 1975, cuando la notario \\ Zajarula Kusulas Tejada se presentó en una asamblea de noventa y nueve docentes \\ universitarios a fin de realizar la protocolización de los Estatutos del Sindicato del Personal \\ Académico de la Universidad Autónoma de Zacatecas. Después vendría la presentación \\ $y$ discusión del primer Contrato Colectivo de Trabajo ante el Consejo Universitario \\ el 2 de febrero de 1976, el registro consiguiente ante la Junta Local de Conciliación \\ y Arbitraje y la conformación del primer Comité Ejecutivo del Sindicato al siguiente año. \\ A cuatro décadas de distancia nada es igual.
}

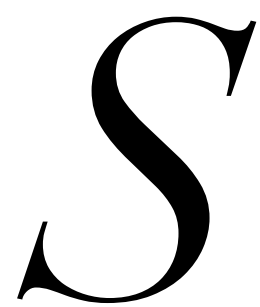

I BIEN LOS AÑOS I97o se ven con nostalgia, $y$ algunos viven a su sombra, el sujeto académico ya no es el mismo; el Contrato Colectivo de Trabajo (ССT) tampoco. El pacto social bienestarista, el llamado "milagro mexicano" (al que Joan Robinson llamó, a principios de los años setenta, un simple "milagro estadístico"), dio paso a las políticas restrictivas, a la desregulación y privatización, a los pactos salariales, en aras de la estabilidad financiera a toda costa. Emerge una estructura de ingresos salariales que depende ya no de la negociación contractual bilateral sino de

\footnotetext{
* Docente-investigador de la Unidad Académica de Economía de la Universidad Autónoma de Zacatecas, México.
}

programas de ingresos complementarios por los cuales hay que competir vía una evaluación cuyas líneas son definidas unilateralmente por la administración. Esta unilateralidad tiende a eliminar un derecho adquirido como es el trabajo de base y la estabilidad en el empleo. Ello ha repercutido negativamente en la organización sindical y en el principio de bilateralidad de las relaciones laborales. Disminuye la negociación colectiva en aras de la negociación individual o grupal, con lo que el Sindicato del Personal Académico de la Universidad Autónoma de Zacatecas (SPAUAZ) corre el peligro de convertirse en una mera oficina de trámites.

Las políticas restrictivas a todas las entidades públicas se han concretado en una disminución neta del subsidio estatal a la Universidad pública, en 


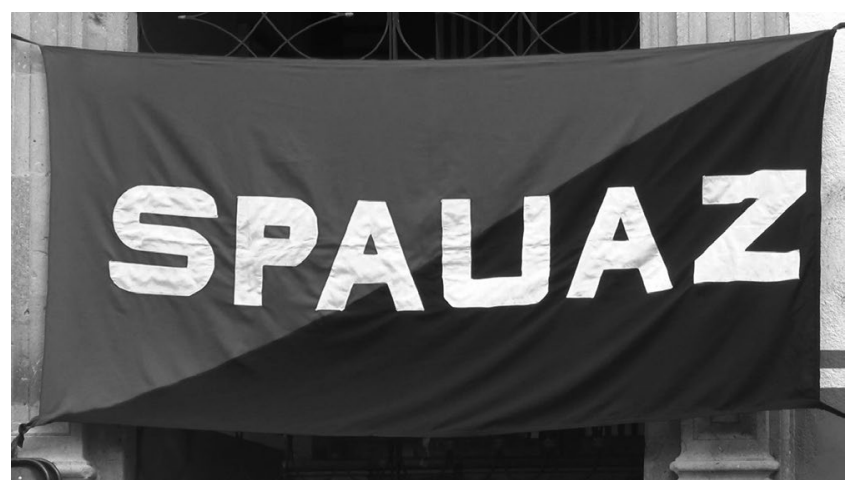

En tanto la modernización educativa incide en la precarización laboral, el socavamiento de la autonomía y la subsunción de la academia, las tensiones político-administrativas se agudizan entre la administración de la UAZ y el SPAUAZ.

un 22 por ciento de $199^{\circ}$ a 2010 . Un retroceso de 30 años que en el caso de la Universidad Autónoma de Zacatecas (UAZ) se manifiesta a partir del año fiscal de i994, por lo que sólo 54 por ciento de la plantilla docente cuenta con respaldo presupuestal. Ha crecido, en cambio, su oferta educativa, por lo que la brecha entre lo soportado presupuestalmente y lo realmente ejercido en cuanto a plazas, prestaciones y las derivadas del régimen de seguridad social, tiende a crecer más que proporcionalmente a los ingresos institucionales. El déficit creciente que de ello resultó dejó a la UAZ en condiciones de gran vulnerabilidad, a tal grado que de ahí en adelante estuvo acotada por las políticas restrictivas en el ámbito financiero y por la modernidad educativa de escaparate en el ámbito académico.

A ello habría que agregar el déficit resultante del régimen de jubilaciones y pensiones de aquellos docentes e investigadores contratados antes del i3 de agosto de I99I - fecha del ingreso del SPAUAZ al Instituto de Seguridad Social al Servicio de los Trabajadores del Estado (ISSSTE) - debido a la ausencia del fideicomiso tripartita que dispone el CCT desde el I4 de febrero de 1992, fecha de la mayor reestructuración y cambios contractuales, derivados del conflicto colectivo de naturaleza económica promovido por la Rectoría en r99i y resuelto a su favor por la Junta Local de Conciliación y Arbitraje (JLCA). En esa fecha el Contrato acepta las disposiciones de la Ley del IsssTe, y de aquí en adelante se plantea ante el SPAUAZ el gran reto de cómo lograr, en el marco de la quiebra del viejo sistema solidario de la seguridad social, una solución integral, institucional y estructural al problema de las pensiones y jubilaciones.
Cabe recordar que, de acuerdo al Contrato Colectivo, las partes se comprometen a constituir un fideicomiso con aportaciones de los Gobiernos federal y estatal, de la propia Institución y del Sindicato, con el objeto de complementar las prestaciones que cubre el ISSSTE y ajustarlas a los montos pactados en el Contrato, así como aquellas que, estando pactadas, no otorga el issste. Es el caso de la jubilación dinámica (la cual es equivalente al último salario devengado y las prestaciones contractuales más todos los aumentos salariales que se dan a los activos), contemplada en el Contrato para los docentes contratados antes del i3 de agosto de r991, y que afronta la institución en un roo por ciento para aquellos que se jubilan a los 25 años de servicio (cualesquiera sea la edad) y durante cinco años más, ya que a los 30 años se hace el trámite ante el Issste, que a partir de ahí se responsabiliza de alrededor de un 6o por ciento de la pensión. Y es el caso que tal fideicomiso tripartita no se ha concretado, en principio por simples razones políticas, esperando que "el de atrás pague", pero también por falta de voluntad política tanto de Rectoría como del Gobierno federal y estatal. Detrás de esto subyace un grave problema de fondo, de estricta índole financiera, que pone en riesgo la estabilidad de la institución y su relación laboral.

No se está en contra de las jubilaciones dinámicas en la Universidad pública. El problema es más económico o financiero; el punto de partida es que el financiamiento de la seguridad social será adecuado si las proyecciones indican que, en cada periodo, los ingresos más las reservas bastan para pagar las prestaciones. Por ende, cuando resulta necesario hacer ajustes en los sistemas pensionarios en un proceso de negociación, se contemplan de inicio la edad de jubilación (al alza) o el incremento de los años de servicio efectivo para acceder a una pensión. Ante los problemas financieros que padece la seguridad social, al parecer irresolubles, el Estado ha decidido rehuir su responsabilidad y se impuso la decisión de que se privatice la seguridad social y se convierta de facto en una seguridad privada individual, el Sistema de Ahorro para el Retiro, gestionado por las Administradoras de Fondos para el Retiro (Afore), que en los hechos significó delegar asuntos públicos a manos privadas pero con un afán de lucro que la vuelve negocio atractivo para los interesados en invertir en ella. Pero la seguridad social - como la seguridad nacional y la salud pública - es un asunto que compete al Estado y es responsabilidad inexorable sólo de éste. Por tanto, nadie debiera asumir hoy cargas pensionarias que suponen un enorme riesgo, ni tiene 
por qué hacerlo, pues para ello existen esquemas nacionales de seguridad social y entes públicos que lo brindan con el soporte del Estado. Menos aún debieran hacerlo las Universidades públicas, pues sin la injerencia directa del Estado no existe ninguna garantía de retiro digno para el ciudadano común, sea o no trabajador universitario.

Cualquier esquema de pensiones en que el Estado no participe está condenado a fracasar tarde o temprano, debido a que los centros educativos fueron pensados y diseñados para brindar educación y cultura, pero no para servir de seguros sociales especiales de sus propios trabajadores.

En suma, la UAZ y el SPAUAZ transitan por un conjunto de tensiones que le dan un rostro álgido a su vida académica, política y administrativa. Es una arena de proyectos en disputa, que se agudiza conforme avanza la llamada modernidad educativa y sus procesos reestructuradores que tienen el sello de la precarización del trabajo, el secuestro de la autonomía y el debilitamiento del ethos académico. Un historiador le llamaría la encrucijada de su historia; para un economista significa el momento decisivo de quiebre e inflexión previo a la catástrofe y a la crisis, pero también previo a la puesta de condiciones para su necesaria reestructuración integral. La pregunta es: ¿a sabiendas de que es necesaria, qué tipo de reestructuración nos permite a todos salir lo mejor librados posible?

La respuesta a esta pregunta debe perfilarse desde la crítica y la autocrítica, poniendo por delante la reafirmación de los valores y los principios fundamentales de la Universidad pública: la autonomía, la gratuidad de su oferta académica y sus servicios, y su compromiso social, gravemente lesionados por las reformas de corte neoliberal, a tal grado que su reestructuración profunda podría darse de acuerdo a los parámetros oficiales a partir de tres condiciones hoy actuantes: la debilidad orgánica de la institución debida a su enorme déficit financiero derivado de un crecimiento espontáneo, no planificado; la división a su interior que impide ofrecer un proyecto integral y un modelo de desarrollo consensuado, y una correlación de fuerzas político-social favorable a la reconversión y a la política restrictiva dirigida a la Universidad pública. Es cierto, la Universidad ha experimentado un crecimiento que si bien es comprensible por la mayor demanda educativa y la complejidad y profundidad en sus actividades, lo ha hecho sin un plan rector de desarrollo y con falta de previsión para afrontar los compromisos contractuales futuros; de ahí el "déficit crónico" de plazas que la Secretaría de Educación Pública (SEP) nunca ha reconocido en términos presupuestales. También gravita negativamente sobre la UAZ la falta de respeto a la normatividad que ella se ha dado y el peso de la grupocracia, además de la apatía y desmovilización de los universitarios que no se involucran en el debate y solución de los problemas.

Revisando el itinerario crítico del SPAUAZ emergen algunas líneas en pro de una propuesta sindical renovada, que pueden enrumbar a la organización gremial hacia la necesaria reestructuración y recuperación de la capacidad sindical de organización, movilización y gestión:

I) No subordinarse - como sí lo hace el sindicalismo blanco, de protección o corporativizado - ni a la SEP ni a la alta burocracia universitaria; buscar mejores condiciones laborales y de ingreso para los docentes sin afectar la productividad y calidad, pues el destino de la Universidad está en juego. Disposición a la interlocución sin diluirse en la perspectiva oficial.

2) Reivindicar la cultura laboral de la eficiencia, productividad y calidad siempre que la institución esté dispuesta al proceso de profesionalización y basificación - definido en forma bilateral - . Toda modernización educativa que trate de mejorar el nivel académico y la pertinencia social de nuestra fuente de trabajo, si no pasa por el mejoramiento de las condiciones de vida y de trabajo de la planta docente, no dejará de ser una mera pretensión retórica.

3) Reconocer la importancia de lograr mejores condiciones presupuestales y materiales de la institución para los trabajadores universitarios, en un contexto de penuria económica, de restricción presupuestal y salarial, de retirada del Estado de la economía.

4) Reconocer que los espacios de formación, preparación y trabajo se han convertido en terrenos importantes de negociación, de confrontación, de lucha y educación para los trabajadores. Ello impone una redefinición de las prioridades sindicales: el espacio del propio proceso de trabajo, que exige la mayor calificación posible, es un terreno de lucha para lograrlo. Con ello se cumplen también las expectativas profesionalizantes de los docentes, el sujeto social básico de la Universidad, y por ende del Sindicato. Es el vínculo entre formación y organización del trabajo en la vida laboral universitaria, es el rescate en sentido sindical de la 
categoría-calificación, en su acepción de control sobre su propio proceso de trabajo, en su cotidianeidad en su centro de trabajo.

5) La reestructuración debe significar un cambio en las relaciones laborales: reestructurar y recomponer al docente en sentido positivo. A la función tradicional del Sindicato (aumento del ingreso salarial, defensa del empleo y mejores condiciones de trabajo), se suma la lucha por el control en la valorización de su trabajo, el ámbito de la productividad y la calidad que ya se planteó. Ello implica que no se limite a la simple denuncia de los efectos de la modernización, $\mathrm{o}$ a la resistencia sin proyecto (que se traduce en resistencia con derrota) o, peor aún, en su aceptación pasiva sin programa alternativo. Si se rechaza tajantemente toda flexibilización y reestructuración, se reproducirá la lógica de la mera denuncia, aunque ahora con menos efectividad, pues si bien los problemas salariales y de democracia sindical siguen vigentes, otros nuevos han aparecido vinculados a la productividad y calidad.

6) En estrecha relación con lo expuesto en el punto anterior, la capacidad de negociación y de la posibilidad de obtener triunfos de parte del Sindicato está fuertemente vinculado con su capacidad para mantener la democracia interna y fortalecer la organización a través de una política de confluencia de esfuerzos. Un sindicalismo con tradición de lucha como el del sector educativo no puede ser la expresión simple de una corriente política, académica o partidaria; debe ser lo que sus miembros exigen que sea en forma democrática. La lucha entre las corrientes debe darse en la base y permitir la doble confluencia enriquecedora entre el Comité Ejecutivo y la base. El respeto a la posición y participación de las minorías debe ser irrestricto, así como estar siempre dispuestos al diálogo en lugar de buscar las marginaciones o la neutralización de los grupos, cualesquiera que ellos sean.

7) Las demandas históricas del SPAUAZ deben seguir en pie: a) revisión y depuración de la plantilla del personal administrativo y de confianza que infla artificialmente la nómina de académicos; $b$ ) aplicación de las cláusulas contractuales que generan ahorros, transparencia y racionalidad en el uso del recurso universitario; c) reestructuración del personal de la administración central; $d$ ) terminación del proceso de basificación a partir de las plazas vacantes definitivas diagnosticadas en las unidades y centros académicos; $e$ ) respeto pleno a la bilateralidad en la determinación de las cargas de trabajo y el ingreso y promoción del personal, y f) certidumbre en el pago de las diversas prestaciones, lo que implica no sólo recuperación presupuestal, sino también un plan de desarrollo universitario. Con ello, el Sindicato pretende abonar a la certidumbre en el futuro del docente, pero también de nuestra fuente de trabajo, en momentos en que se encuentran en riesgo varias prestaciones, la estabilidad financiera y aun la Universidad como la conocemos.

8) El sindicalismo universitario sabe que no es posible cambiar la problemática salarial, el deterioro de las condiciones laborales, la modernización educativa inducida desde fuera y las políticas restrictivas hacia el subsidio de la educación superior de una manera aislada. Se requiere la configuración de un sindicalismo de la educación superior verdaderamente nacional y una amplia concertación social y política, que ha cobrado bríos ante la modificación pro-patronal de la Ley Federal del Trabajo. Los tiempos que corren no son de confrontación interna; requieren de la más amplia voluntad unitaria para hacer frente a las secuelas de las políticas modernizadoras que afectan a los trabajadores académicos al pretender mutilar los derechos laborales plasmados en el Contrato Colectivo y recomponer unilateralmente las expectativas de ingreso y promoción del docente.

En este acercamiento a la solución de la problemática no se diluye la perspectiva sindical en la institucional; el Sindicato tiene sus objetivos y prioridades, como representante de los trabajadores académicos y sus derechos laborales; el reto es cómo obtener las mejores condiciones para la institución y sus trabajadores, en una situación económica adversa, con la política de los topes salariales y la deshomologación salarial y un subsidio disminuido en función de sus necesidades reales. 